\title{
The infocommunication system requirements of the deployable rapid diagnostic laboratory support “sampling group” I.
}

\author{
FARKAS Tibor ${ }^{1}$, HRONYECZ Erika²
}

\begin{abstract}
The purpose of the authors of this article is to present the abilities and the requirements of the infocommunication sub-system of a sampling group which supports the professional activity of a deployable rapid diagnostic laboratory. In addtion, the article determines the infocommunication demands and the contact system of the group. Considering the above, the authors of the article investigate the applicable technologies, the possible technical devices and give suggestions for their implementation.

This article is made possible with the support of the project TGYDGL09 "Deployable Rapid Diagnostic Laboratory”.
\end{abstract}

\section{Introduction}

The rapid diagnostic laboratory, implementable in a standard 22-foot container, is a tool system which is capable of eliminating the consequences of bio-terrorism and answering issues of health and food, and increasing the efficiency of biological risk management.

In the case of an occurred biological risk or infection it may be necessary to deploy a mobile biological analysis laboratory which would be installed near the location of the infection to process the samples from the pathogens and detect the presence of the pathogens in order to enforce the management decisions in relation to the risk management procedures and protocols.

In order to support all of these, a mobile sampling group strengthens the bio-laboratory. Its task is sampling from a specified area. The purchase taking of the samples from the possibly contaminated area forms the basis of the laboratory work, as the main task and basic purpose of the bio-laboratory is to process and analyse them.

It is necessary to establish a communication link between the sampling group and the bio-laboratory in order to facilitate the appropriate amount and quality of information exchange. One of the subfields of the communication sector of the bio-laboratory is keeping contact with the sampling group which helps the professional management. Providing all kinds of information exchange promotes exact task-execution.

Another element of the communication system of the bio-laboratory is an internal communication system and a network which ensures the contact development with the lead and command management. All of these should be established taking into account the above mentioned requirements.

1 farkas.tibor@uni-nke.hu, National University of Public Service, Budapest, Hungary

2 hronyecz.erika@gmail.com, National University of Public Service, Budapest, Hungary 
The sampling unit is a group equipped with special sampling devices and other additional components (see on Figure 1.). It moves via motor vehicles, possibly by aircraft (helicopter). Its members carry out various sub-tasks during the sampling which are an important influence factor in the planning of the establishment of the communication system. Beyond the sampling they perform the appropriate (temporary and safe) storage of samples and the reliable delivery of them to the deployable laboratory.

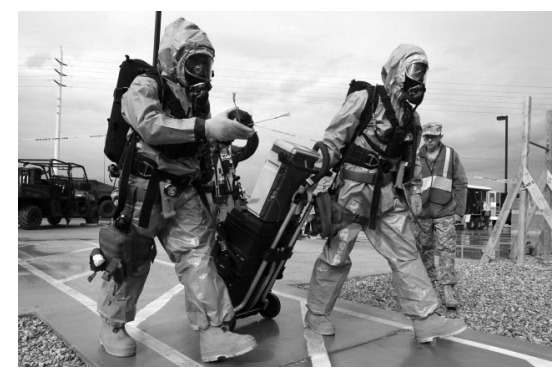

Figure 1. Sampling Group [1]

\section{The communication link between the sampling group and the bio- laboratory}

The factors which affect the establishment of the infocommunication system of the sampling group are greatly narrowed by the usable systems and devices. Accordingly, we need to examine the communication basics and the physical location of the group and its members during the performance of the tasks.

To properly ensure the system of communication services it is necessary to specify the communication needs before we determine the system requirements. Considering the links and connections of the sampling group, it has to serve two directions according to the determined requirements:

- the relation between the sampling group and the bio-laboratory (external communication);

- the internal communication of the sampling group.

There is a significant difference between the two directions in terms of the distance and the service requirements. According to the previous examinations and the communication needs it is necessary to ensure a long distance connection between the group and the bio-laboratory as the distance between the location of the sampling and the place of the processing of the sample can be tens of kilometres. The communication tools and systems need to be chosen correspondingly.

The essential criterion of rapid and precise task execution is a quick and simple connection because the installation and operation of complicated communication tools is not practical as the bio-laboratory is not reinforced by infocommunication professionals. The large space requirement of a big and complex communication system is a negative factor as well, since the size of the bio-laboratory is limited and the placement of a large number of laboratory and mechanical equipment is a priority. 
In accordance with all of these, a communication tool should be provided - for the sampling group - which is easy to use, small sized and offers a proper connection with the bio-laboratory and with the sampling group as well. The communication channel between the sapling group and the bio-laboratory should provide a voice based communication. Voice connection is an important element of the communication between the two parties because professional governance and support can be done through it. Besides the transmission of issued orders for the sampling group, it is important that the group leader report and send information to management for defining further tasks.

Another important possibility is the realization of data communication. Besides the oral tasking and reporting, the transformation of certain data may be necessary to help to process the samples in the future. A datasheet - filled out by the leader of the sampling group concerning the sample and sampling can be an example of data recording. After acquisition the determined samples must be examined for data for the easier start-up of a later investigation. It can be recorded in a pre-defined datasheet. (see on Figure 2.) One of these datum can be the amount of samples, the sampling location, the sampling date, the type of samples etc.

\section{Asbestos Air Sampling Data Sheet}

\begin{tabular}{|c|c|c|c|c|c|c|c|c|}
\hline $\begin{array}{l}\text { Sample } \\
\text { Number }\end{array}$ & Date & $\begin{array}{l}\text { Sample } \\
\text { Time }\end{array}$ & $\begin{array}{l}\text { Air } \\
\text { Flow }\end{array}$ & $\begin{array}{l}\text { Type of } \\
\text { Sample }\end{array}$ & $\begin{array}{l}\text { Employee Name } \\
\text { (If personal sample) }\end{array}$ & $\begin{array}{l}\text { Pump Type and } \\
\text { Pump ID number }\end{array}$ & Sampling Protocol & Comments \\
\hline & & $\begin{array}{l}\mathrm{ON} \\
\text { OFF } \\
\text { Total (min) }\end{array}$ & $\begin{array}{l}\text { Start } \\
\text { Stop } \\
\text { Avg }\end{array}$ & $\begin{array}{l}\square \text { Personal } \\
\square \text { Area } \\
\square \text { Pre-Abatement } \\
\square \text { clearance }\end{array}$ & & $\begin{array}{l}\square \text { Gast } \\
\square \text { Gilian } \\
\square \text { Other: }\end{array}$ & $\begin{array}{l}\square \text { ID-160 } \\
\square \text { NIOSH } 7400 \\
\square \text { NIOSH 7402 } \\
\square \text { other: }\end{array}$ & \\
\hline \multirow[t]{2}{*}{$\begin{array}{l}\text { Sample } \\
\text { Number }\end{array}$} & Date & $\begin{array}{l}\text { Sample } \\
\text { Time }\end{array}$ & $\begin{array}{l}\text { Air } \\
\text { Flow }\end{array}$ & $\begin{array}{l}\text { Type of } \\
\text { Sample }\end{array}$ & $\begin{array}{c}\text { Employee Name } \\
\text { (If personal sample) }\end{array}$ & $\begin{array}{l}\text { Pump Type and } \\
\text { Pump ID number }\end{array}$ & Sampling Protocol & Comments \\
\hline & & $\begin{array}{l}\text { ON } \\
\text { OFF } \\
\text { Total (min) }\end{array}$ & $\begin{array}{l}\text { Start } \\
\text { Stop } \\
\text { Avg }\end{array}$ & $\begin{array}{l}\square \text { Personal } \\
\square \text { Area } \\
\square \text { Pre-Abatement } \\
\square \text { Clearance }\end{array}$ & & $\begin{array}{l}\square \text { Gast } \\
\square \text { Gilian } \\
\square \text { Other: }\end{array}$ & $\begin{array}{l}\square \text { ID-160 } \\
\square \text { NIOSH } 7400 \\
\square \text { NIOSH } 7402 \\
\square \text { other: }\end{array}$ & \\
\hline \multirow[t]{2}{*}{$\begin{array}{l}\text { Sample } \\
\text { Number }\end{array}$} & Date & $\begin{array}{l}\text { Sample } \\
\text { Time }\end{array}$ & $\begin{array}{l}\text { Air } \\
\text { Flow }\end{array}$ & $\begin{array}{l}\text { Type of } \\
\text { Sample }\end{array}$ & $\begin{array}{c}\text { Employee Name } \\
\text { (If personal sample) }\end{array}$ & $\begin{array}{l}\text { Pump Type and } \\
\text { Pump ID number }\end{array}$ & Sampling Protocol & Comments \\
\hline & & $\begin{array}{l}\mathrm{ON} \\
\mathrm{OFF} \\
\text { Total (min) }\end{array}$ & $\begin{array}{l}\text { Start___ } \\
\text { Stop__ } \\
\text { Avg }\end{array}$ & $\begin{array}{l}\text { Personal } \\
\square \text { Area } \\
\square \text { Pre-Abatement } \\
\square \text { clearance }\end{array}$ & & $\begin{array}{l}\square \text { Gast } \\
\square \text { Gilian } \\
\square \text { other: } \\
\end{array}$ & $\begin{array}{l}\text { ID-160 } \\
\square \text { NIOSH } 7400 \\
\square \text { NIOSH } 7402 \\
\square \text { other: }\end{array}$ & \\
\hline \multirow[t]{2}{*}{$\begin{array}{l}\text { Sample } \\
\text { Number }\end{array}$} & Date & $\begin{array}{l}\text { Sample } \\
\text { Time }\end{array}$ & $\begin{array}{l}\text { Air } \\
\text { Flow }\end{array}$ & $\begin{array}{l}\text { Type of } \\
\text { Sample }\end{array}$ & $\begin{array}{l}\text { Employee Name } \\
\text { (If personal sample) }\end{array}$ & $\begin{array}{l}\text { Pump Type and } \\
\text { Pump ID number }\end{array}$ & Sampling Protocol & Comments \\
\hline & & $\begin{array}{l}\mathrm{ON} \\
\mathrm{OFF} \\
\text { Total }(\mathrm{min})\end{array}$ & $\begin{array}{l}\text { Start___ } \\
\text { Stop___ } \\
\text { Avg }\end{array}$ & $\begin{array}{l}\square \text { Personal } \\
\square \text { Area } \\
\square \text { Pre-Abatement } \\
\square \text { clearance }\end{array}$ & & $\begin{array}{l}\square \text { Gast } \\
\square \text { Gilian } \\
\square \text { other: } \\
\end{array}$ & $\begin{array}{l}\square \text { ID-160 } \\
\square \text { NIOSH } 7400 \\
\square \text { NIOSH } 7402 \\
\square \text { other: }\end{array}$ & \\
\hline \multirow[t]{2}{*}{$\begin{array}{l}\text { Sample } \\
\text { Number }\end{array}$} & Date & $\begin{array}{l}\text { Sample } \\
\text { Time }\end{array}$ & $\begin{array}{l}\text { Air } \\
\text { Flow }\end{array}$ & $\begin{array}{l}\text { Type of } \\
\text { Sample }\end{array}$ & $\begin{array}{c}\text { Employee Name } \\
\text { (If personal sample) }\end{array}$ & $\begin{array}{l}\text { Pump Type and } \\
\text { Pump ID number }\end{array}$ & Sampling Protocol & Comments \\
\hline & & $\begin{array}{l}\text { ON } \\
\text { OFF } \\
\text { Total (min) }\end{array}$ & $\begin{array}{l}\text { Start___ } \\
\text { Stop___ } \\
\text { Avg }\end{array}$ & $\begin{array}{l}\square \text { Personal } \\
\square \text { Area } \\
\square \text { Pre-Abatement } \\
\square \text { Clearance }\end{array}$ & & $\begin{array}{l}\square \text { Gast } \\
\square \text { Gilian- } \\
\square \text { Other: }\end{array}$ & $\begin{array}{l}\square \text { ID-160 } \\
\square \text { NIOSH } 7400 \\
\square \text { NIOSH } 7402 \\
\square \text { other: }\end{array}$ & \\
\hline
\end{tabular}


FARKAS Tibor, HRONYECZ Erika: The infocommunication system requirements...

Chemistry Water Sampling Data Sheet

\begin{tabular}{|c|c|c|c|c|c|c|c|c|c|}
\hline \multicolumn{4}{|l|}{ Date: } & \multicolumn{5}{|c|}{ Time:_ } & \\
\hline \multicolumn{10}{|c|}{ Weather Conditions: } \\
\hline \multicolumn{3}{|c|}{ Wind Direction: } & \multicolumn{2}{|c|}{ Wind Speed: } & & \multicolumn{3}{|c|}{ Air Temp $\left({ }^{\circ} \mathrm{C}\right)$} & \\
\hline \multicolumn{10}{|c|}{ Station/Site:_ } \\
\hline $\begin{array}{l}\text { Sampling } \\
\text { Location }\end{array}$ & $\begin{array}{l}\text { Depth } \\
\text { (m) }\end{array}$ & $\begin{array}{c}\text { Temp, } \\
{ }^{\circ} \mathrm{C}\end{array}$ & $\begin{array}{l}\text { Specific } \\
\text { Gravity }\end{array}$ & \begin{tabular}{|c|} 
Salinity \& \\
Hydrometer \\
Chart
\end{tabular} & Refractometer & $\mathrm{pH}$ & D.O. & Chloride & $\mathrm{CO}_{2}$ \\
\hline \multicolumn{10}{|l|}{ Top } \\
\hline Bottom & & & & & & & & & \\
\hline
\end{tabular}

Observations:

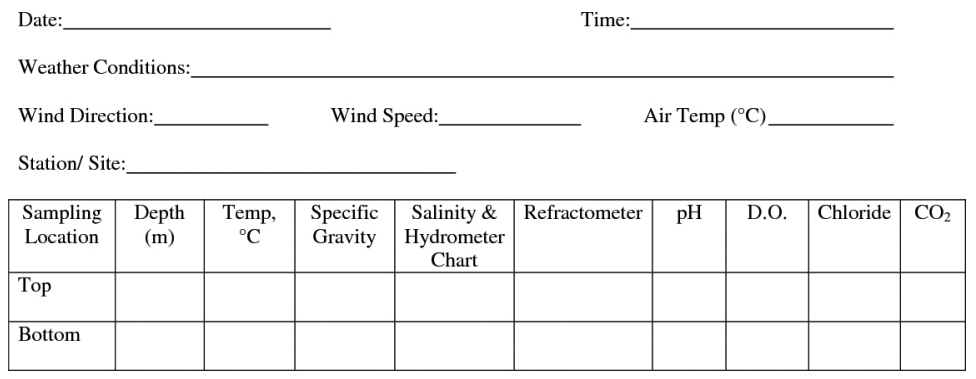

Observations:

Figure 2. Sampling data sheet [2]

In addtion, pictures or videos can be taken of the samples or of the location, this helps the preparation of the processing of samples, the action of processing, archiving, or makes possible inspections, investigations. The personal equipment of the members of sampling unit should be installed with a camera which is able to take photos or record moving pictures of the process (see on Figures 3.). Naturally it helps the professional ordinance of the sampling group if the group leader is able to control the workflow from the background. 


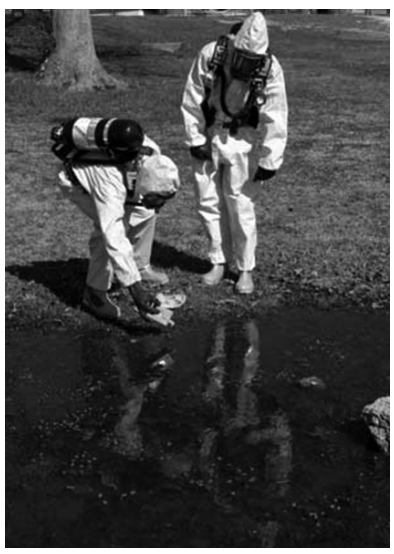

Figure 3. Sampling method [3]

It is a significant factor that it has to be able to communicate in an area without communication infrastructure. The satellite link is one of the most suitable solutions for establishing a connection. Its advantage is that it is less sensitive to the terrain conditions and it has a high capacity of availability, but its major disadvantage is the huge traffic charge. Satellite communication has a great importance both in civilian and in military (defence) signal areas. The currently applicable satellite phones can provide all requirements which are necessary nowadays in a modern infocommunication society and also suitable for serving the bio-laboratory. Therefore the satellite data transfer allows continuous, highly reliable voice and data traffic between the users and the remote endpoints.

Over all, in terms of the communication among the bio-laboratory and the sampling unit, based on the existing needs and expectations, an integrated voice and data connection providing technology should be selected from among wireless connection types. As described above, microwave connection provides opportunities beyond the satellite connection forms. Microwave connection can be workable on Ethernet interface so the long distance microwave connection can be established between information technology (communication) devices which are used in civilian life. "Ethernet is the most widely used local area network protocol (LAN). Its defined standard is 802.3. Ethernet was originally developed by Xerox, its initial form called Aloha net [...] Nowadays the most commonly used Ethernet protocols are the 10 Mbps and 100 Mbps versions. [...] Recently the 1000 Mbps, gigabit versions are widely spread." [4] It always provides the connection between the endpoints, allowing a fast and secure voice, data and image transmission. With the VPN ${ }^{3}$ service which is based on MPLS ${ }^{4}$ protocol the secure connection form is available which is allowed by developed virtual circuits which exclude unauthorized access to data and information. In our view, the secure exchange of data and the exclusion of unauthorized persons are highly important requirements at all levels and in all directions of connection. Secure and protected communication is the basic condition of the successful operation, even if the laboratory carries out non-military but civilian tasks. A good example of a leak is when a civilian "captures" a message which contains information about the samples, it can create a panic among the public, forwarding

3 Virtual Private Network

4 Multiprotocol Label Switching 
misunderstood information. In our opinion, its use in this project is not the most appropriate way because a direct line of sight (LOS) is necessary between the microwave antennas and it needs complex visibility testing and an antenna (mast) kit and it significantly affects the place of the operation. Therefore a professional specialist with complex knowledge is necessary during the planning, installation and operation, something not available in the capapcity of the bio-laboratory. In our view, the high-speed, high-throughput microwave link can be definitely useful as a second connection.

The wireless connection form with radios can also be achieved between the two parties. In this case, considering the large distance, the short-wave (HF) radio connection can be implemented. The radio equipment is excellent for voice communication, but only slightly suitable for data transmission because the transfer speed is not sufficient to transfer images and moving pictures. The modern, currently applied antenna types can easily be used because of their small size but the bridging of the large distances mostly can be achieved only with complex antennas. It is important that these radios generally should be easy to handle (user level), with highly efficient and fast tuning. During the application of radio links the frequencies to be used should be taken into account in every case as their use requires authorization. ("Appointing frequency is possible according to the government regulation about the national allocation of frequency bands within the using rules established in a regulation by the Minister. The allocation of frequency bands is determined by government regulation in accordance with international agreements and EU sources of law." [5]). Accordingly, the radio signal is very well applicable during military use of the bio-laboratory, when the nation uses its own operational radio devices and the corresponding antenna kit. We need the safety factors to take into account the case of radio connections (applying all wireless connections),to insure that the information will be only accessed by the specified persons. The security issue is naturally a particular field in the world of infocommunication but a kind of information defence base can be realized with the decrease of spreading radio waves. The spread of radio waves can be limited by using controlled antennas. The radiation area is decreased with the right force and control, and therefore the covered area can be optimized.

Those devices which work on unlicensed frequency ${ }^{5}$ ranges are easily accessed by civilians. This may be appropriate but there is a risk of mutual interference with other devices but it can be minimalized with careful planning thereby making it very applicable.

It is important to highlight — from the other forms of connection - the use of a GSM network which is one of the most widely used communication ways nowadays. The mobile network is a continuous developing area of modern telecommunication which provides various services after classic phone calls. Besides voice calling, advanced devices are capable of data transforming, video calls and establishing Wi-Fi contact. Its big advantage is that the mobile network is available almost everywhere (because of high national coverage). Nowadays, the devices can establish a high-speed data connection (3G; 4G) which provides smooth data transfer. The new technology supports mainly data contact and data communication because it requires a higher speed and higher throughput.

The 3G (4G) cellular systems can complement each other well with the local networks (for example: LAN). The 3G can allow services and applications such as playing high-defini-

5 ISM: Industrial — Science — Medical band: The 2,4 GHz band usable for establishing radio frequency connections without any official permit. Several common devices radiate in this band, so we must account for the interference. 
tion videos, video conferencing, or fast internet access. The 4G services provide a $326 \mathrm{Mbit} / \mathrm{s}$ theoretical maximum transfer rate — with high mobility — for the users. It supports the

internet connection and online television, in addtion to the "classic" phone calls. According to these, we have to analyze the modern GSM services as a corresponding communication solution. The usability across national borders is guaranteed as the roaming service insures passing across the mobile networks of several nations. However, the channel is opened, the encryption and the covering of the transmission of the data is not appropriate. Apart from this, it can be an excellent duplication of a given communication channel, of a satellite contact for example.

In summary, satellite communication which is capable of large distances, is mainly used for voice but also data connection, it is usable in every circumstance and its geographical capability is the best choice with reserved radio or GSM connection. In case of military applications using their own tactical radios is expedient.

\section{The external satellite communication of the sampling group}

As previously mentioned, it is necessary to establish voice communication between the mobile sampling group and the deployable rapid diagnostic laboratory. Therefore, the bio-laboratory should have satellite communication, so it is best to realize the connection between the group and the laboratory by using this method.

The satellite systems provide two-way communication data transfer between the satellite and the terrestrial user. We need a system formed with telecommunication satellites for establish the satellite communication. Their aim is to ensure telecommunication. The majority of telecommunication satellites are in geosynchronous orbit ${ }^{6}$ which has the big advantage that it is orbiting with the same orbital speed of the Earth and it seems always to be at the same point from the Earth. It greatly facilitates the establishment of a satellite connection. It is enough to set the terrestrial antenna to the satellite and the established connection remains constant. The GEO orbit means an approximately $35800 \mathrm{~km}$ altitude above sea level. The other satellites which are orbiting in the same altitude are the geostationary satellites ${ }^{7}$ but the difference is that those move at the level of the Equator. For the implementation of satellite communication, transmitter and receiver stations and terrestrial observation stations are necessary which carry out the monitoring of the system and the satellites. A relatively large area of the territory of the Earth (approximately 40-45 \%) can be covered by the satellites which operate at this altitude. This allows the communication system to operate with a small number of satellites.

The satellites installed by the company Thuraya operate at this altitude and are capable of establishing contact between the sampling group and the bio-laboratory. "The Thuraya -3 satellite was built by the company Boeing Satellite System and began a geosynchronous orbit on 15 January 2008 at $154^{\circ}$ west longitude. The Thuraya mobile satellite system was built by the Boeing Satellite System (formerly: Hughes Space and Communication International, Inc, or HSCI) for about 1 billion USD worth. Its planned life is 12-15 years. The Thuraya-1 and 2 satellites are at $44^{\circ}$ to the east in geostationary orbit." [6] The hand-held satellite phones are ideal for information exchange based on our recommendation and taking the primary voice communication needs into account.

6 GEO: Geosynchronous Earth Orbit

7 GSO: Geostationary Earth Orbit 


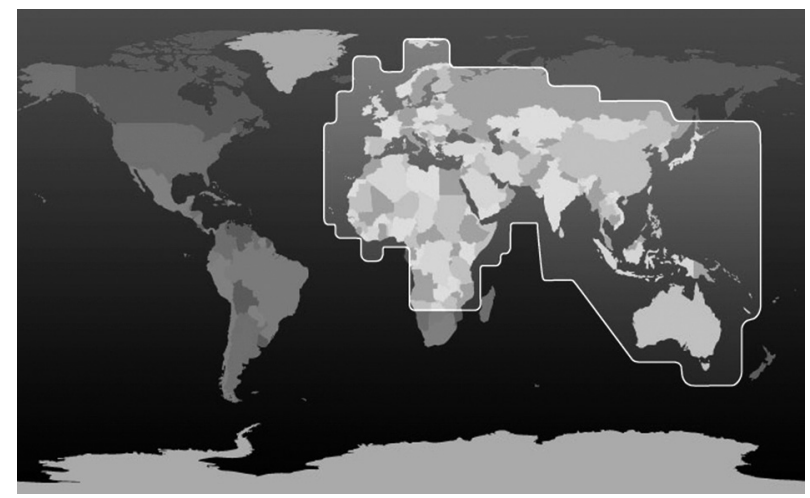

Figure 4. Thuraya coverage map [7]

It is necessary to provide a kit of Thuraya XT-Dual phone for the mobile sampling group which is water-, shock- and dust resistant and suitable for application at a GSM band (900/1800/1900 MHz) besides satellite connection. This is an excellent option in the case of the mobile network coverage appropriate in the region. In this case the satellite communication can be omitted which carries out a cost-effective connectivity. Naturally, in those areas where the terrestrial infrastructure is not available, the satellite connection is realizable. The Thuraya XT-dual device is usable for communication while moving without significant loss of satellite signal, thanks to the advanced technology, its special antenna and the extremely strong system. It is also possible to use in-vehicle by a connect to the car kit. It has high talk and stand-by time and is suitable for data transfer along with voice communication. It has Bluetooth and message sending functions (SMS, MMS, e-mail, Fax), and emergency SMS function. The great advantage of the device is that it can receive satellite calls with a covered antenna so the significance of this device is portability.

The fitting of the other station (bio-laboratory) with Thuraya XT-Dual devices maintain the satellite or GSM connection between the two parties. The bio-laboratory needs a device which ensures the connectivity in indoor space (inside the container). An indoor transceiver has to be installed inside the container which can establish contact with the help of an antenna installed on the outside of the container. This could be the FDU XT-Dual device which is a fix established docking station, with which the telephone device becomes capable of communication. With the use of FDU we can realize full-featured fax, voice and data communication and the loading of the device is also solvable. 


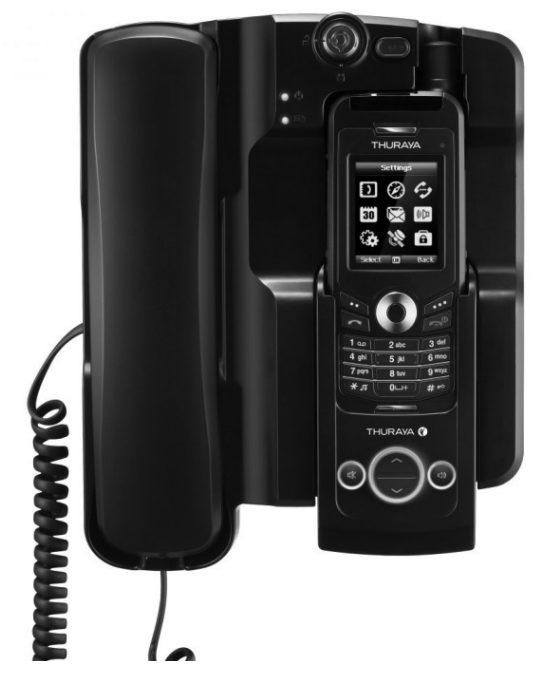

Figure 5. Thuraya FDU and XT-Dual [8]

The above described device is excellent for serving the sampling group's communication needs. Although there are many devices to choose from, in our opinion the devices made by Thuraya, in the present case, have several positive characteristics. [9]

\section{The external microwave communication of the sampling group}

A possibility for an installed contact between the sampling group and the bio-laboratory as a duplicate of the satellite (and GSM) contact is microwave link. Microwave is an electromagnetic wave which is between 1 meter and 1 millimetre and its frequency is higher than 300 $\mathrm{MHz}$ and lower than $300 \mathrm{GHz}$. Nowadays, the increasing spread of devices for information exchange mainly use the lower part of the range of frequency for communication and telecommunication. Today, companies and individuals often use such tools which have mainly been characterized by telecommunication service providers.

The microwave link provides all the requirements which must be supported by the communication system of the bio-laboratory. It provides a constant, reliable connection for long distances between the endpoints and its high-speed data connection allows the voice, image, video and videoconferencing communication. The GSM phones, the Bluetooth devices, the devices for wireless data transmission (WLAN), the television and radio systems and the satellite stations also use microwave transmission.

The disadvantage of the microwaves is that a line of sight is needed for the installation of connection. Landmarks in their way can obstruct, absorb or force their deflexion. Of course, the deflected signals can reach the destination between the transmitter and the receiver antenna in another way. This phenomenon exists because the microwave tufts spread in the air not by point so the extent of the tufts should be taken into account during the planning. We also have to take into account that there are different zones in which the deflected signals are in phase, that is to say, are not in phase with the central signal. These are called Fresnel-zones. (see on Figure 6). 


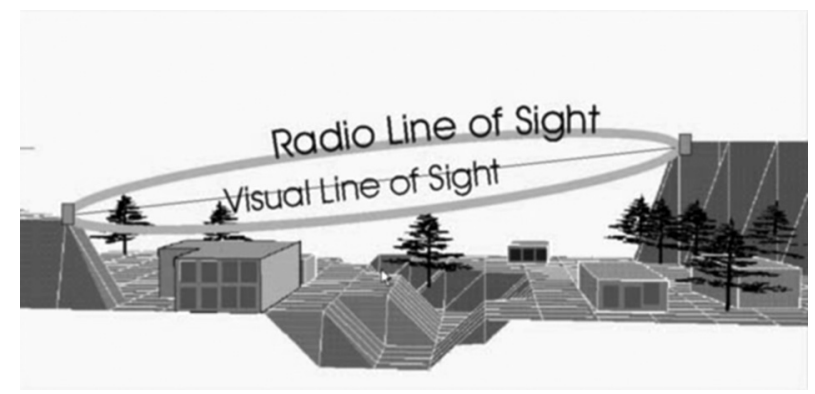

Figure 6. Line of Sight [10]

The secure establishing of the connection is realizable with encrypted, closed-channel microwave management. This type of connection has the same characteristics as the wire networks so it is very well able to establish temporary connections which can replace a wire network. The range is extendible by using higher gain antennas and a Point to Point or a $\mathrm{PMP}^{8}$ connection is also established. The Point to Point connections are suitable for bridging distances more than tens of kilometres with high-speed data transmission speed. Besides the use of 5GHz ISM bands, we can use the frequency bands designated by the National Media and Communications Authority. Most of the small sized, deployable antennas have IDU-ODU ${ }^{9}$ systems, which include indoor and outdoor units. It operates on the principles of SNMP $^{10}$ and support Qos services and bandwidth management in order to be effective.

The implementation of the communication between the bio-laboratory and the sampling group can be executed by establishing a Point to Point contact. A reliable and secure connection can be achieved in any environment, field and weather conditions. The contact established by Ethernet microwave antenna can operate as a wireless bridge. The alvarion microwave (Ethernet) antenna can be tools which can appropriately serve the requirements. The connection is also realizable with different organizing principles. If possible, we can connect to public networks ${ }^{11}$ with the antenna and these might provide a wider range of connection.

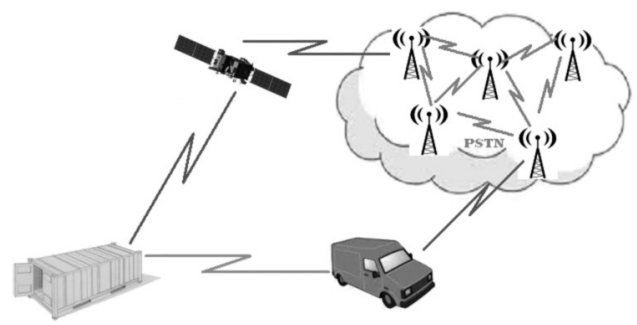

Figure 7. Two microwave links between sampling group and laboratory (source: own)

8 Point Multi-Point

9 Indoor Unit - Outdoor Unit

10 Simple Network Management Protocol

11 PSTN: Public Switched Telephone Network 
The alvarion antenna operates in a time-division duplex mode which allows separated two-way communication (uplink/downlink) in a same frequency using different time slots. The antenna uses ODFM ${ }^{12}$ channel access methods with error correction coding. ${ }^{13}$

Thanks to the advanced multipath contact of the ODFM, the system does not need a direct line of sight between the antennas. The system supports other adaptive modulation methods such as the BPSK ${ }^{14}$ the QSK, or the quadrature amplitude modulation (16, 64 QAM).

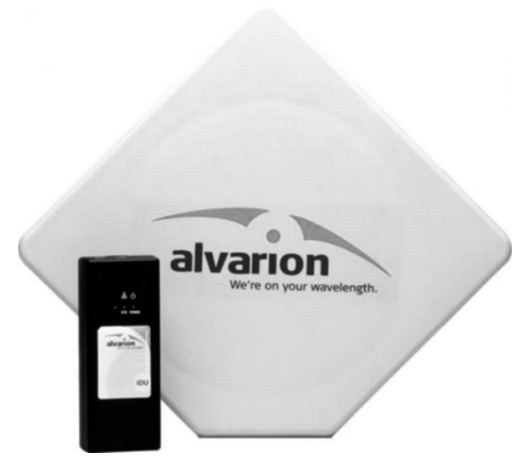

Figure 8. IDU and ODU units of alvarion Ethernet antenna [11]

The antenna can be configured with encrypted/authenticated channels, with WEP ${ }^{15}$, or $\mathrm{AES}^{16}$ algorithm and with 128-bit key. Basic protection can be achieved with these methods, but it is only the configuration of antennas used transmission path that can be supplemented with other security solutions.

The system supports the virtual networks with the service IEEE 802.11Q VPN ${ }^{17}$. This is a so-called tunnelling-technic and it ensures that the information forwarding will be hidden. We call VPN that network in which the transmission of data is made through a public infrastructure while the data remain confidential.

\section{Conclusion}

The first step of the tasks of the rapid diagnostic laboratory is sampling. The sampling process has to be started after the relocation of the bio-laboratory, which is a long and complex process and which needs professional support.

The sampling team collects the samples from the specified field section or the contaminated area; brings them to the laboratory where the analysis is executed. If they have more information it helps the biological examinations. The communication system of the bio-laboratory should forward this information.

12 Orthogonal Frequency Division Multiplexing

13 FEC: Forward Error Correction

14 Binary Phase-shift Keying

15 Wired Equivalent Privacy

16 Advanced Encryption Standard

17 Virtual Private Network 
The information link of the sampling group defines two main directions. One of them is the direction of the bio-laboratory which is implemented mainly with satellite connection. The satellite connection ensures the voice- and data connection between the two endpoints which can be implemented by Thuraya XT-Dual device. If possible, the device is able to connect to GSM networks. The microwave Ethernet connection is able to duplicate the link established by satellite phone device, which allows a long-distance voice and data connection with the help of the connected computer or telephone.

The overall conclusion is that the infocommunication system of the sampling group which operates as a part of the deployable rapid diagnostic laboratory is a complex system which applies various technology and technical devices.

\section{References}

[1] ANDERSON, K.: Army North's CSTA puts Nevada CBRN team through paces. http://www.army.mil/article/95202/Army_North_s_CSTA_puts_Nevada_CBRN_team_ through_paces/ (downloaded: 2008 2013)

[2] http://www.docstoc.com/docs/105611170/Chemistry-Water-Sampling-Data-Sheet (downloaded: 2008 2013)

[3] CBRN Hazard Sampling Assesment. http://www.cbrn.info/hazard-sampling-assesment.php (downloaded: 2408 2013)

[4] http://itszotar.hu/?q=246 (downloaded: 2105 2013)

[5] KOVÁCS V. G.: Frekvencia használat jogi háttere. http://www.kovacsvg.hu/C_Frekvencia. html (downloaded: 2105 2013)

[6] http://www.gpscom.hu/cikk.php?id_menu=402 (downloaded: 0407 2013)

[7] http://www.satphone.co.uk/networks/thuraya/coverage (downloaded: 0507 2013)

[8] http://www.iec-telecom.com/?item=product\&id=34\&lang=en (downloaded: 0507 2013)

[9] http://thuraya.com/sites/default/files/Satphone\%20Comparison\%202013_0.pdf (downloaded: 0507 2013)

[10] Cálculo de Zona de Fresne.l http://tamax.com.ar/blog/?p=517 (downloaded: 2708 2013)

[11] Alvarion breeznet B10 (backhaul). http://www.bluevisiontelecom.be/services/alvarion (downloaded: 2708 2013) 